\title{
Tugas Manusia dalam Dunia Milik Tuhan ${ }^{1}$
}

\author{
Nitis Harsono \\ Sekolah Tinggi Teologi Indonesia Timur Makassar, Indonesia \\ Email: nitisharsono03@gmail.com
}

Diterima: 19 Maret 2020

Direvisi: 12 Mei 2020

Disetujui: 11 Juni 2020

\begin{abstract}
Abstrak
Bertolak dari pergumulan yang seolah tarik menarik bagi diri Gereja, oleh karena ia sadari bahwa di satu sisi bangsa ini diperhadapkan pada pergumulan yang masih belum terselesaikan, sebagaimana cita-cita para founding fathers yang tertuang dalam Mukadimah UUD 1945, yakni mewujudkan rakyat yang cerdas, sejahtera, bangsa yang berdaulat sehingga berperan dalam mewujudkan perdamaian dunia. Cita-cita tersebut menjadi konteks nasional, yakni masalah besar bangsa ini, yang sekaligus menjadi medan kehadiran Gereja. Di pihak lain, Gereja bergumul dan merasa dirinya terpisah dari bangsa ini, merasa bukan bagian dari dunia ini. Barangkali pikiran ini muncul karena merasa banyak penolakan terhadap dirinya, sehingga enggan, atau paling tidak membatasi dirinya bergaul dengan masyarakat. Tentunya bisa juga dimaklumi, penolakan terhadap kekristenan tak lepas dari sejarah. Tetapi kira-kira bisa jadi penolakan ini hanya di sebagian dari luasnya bentangan wilayah negara kesatuan Republik Indonesia, dan bisa jadi juga merupakan prasangka. Rasa tarik-menarik tadi adalah kesadaran akan lingkungan atau medan sekitar Gereja yang perlu mendapat perhatian dari karya Gereja. Gereja memang dipandang liyan (asing), bukan dari dunia, tetapi ia menjadi warga dunia itu. Gereja sadari bahwa ia harus hadir bagi dunia, meski di lain pihak condong lebih memerhatikan pergumulan dirinya. Teks Yeremia 29:7, menjadi acuan teologis untuk membangun dan menggugah spiritualitas Gereja menjadi karya iman yang
\end{abstract}

${ }^{1}$ Judul ini penulis pinjam dari judulnya buku karya Malcolm Brownlee, terbitan BKP. Gunung Mulia Jakarta, 1898. Buku itu sendiri merupakan buku etika yang sangat bagus dan penulis anjurkan untuk dimiliki oleh para pengerja gereja maupun warga jemaat.

Copyright@2020; Fidei: Jurnal Teologi Sistematika dan Praktika, e-ISSN: 2621-8135, p-ISSN: 2621-8151|88 
konkrit bagi lingkungannya. Karya iman Gereja bagi lingkungan sesungguhnya turut mengatasi pergumulan bangsa, yang tak terpungkiri dengan sendirinya memberi dampak bagi kelangsungan kehadiran Gereja.

Kata-Kata Kunci: Kemakmuran; Ketahanan bangsa; Karya Gereja; Pengutusan; Sejahtera.

\section{Abstract}

Depart from a struggle that seemed to be conflicting of each other in the Church itself, the Church realized that on one hand this nation was confronted with an unresolved yet struggle, as the ideals the founding fathers stated in the Preamble of the 1945 Constitution, namely to actualize an intelligent, prosperous, a sovereign nation that plays role in actualizing world peace. These ideals become a national context, on which a big problem of this nation laid, however at the same time a field of the Church to presence. On the other hand, the struggle of the Church is to feel itself being separated from this nation and feeling apart of this world. Perhaps this thought arises because the Church feels a lot of rejections that brings it feels reluctant and restrict itself of associating with society. This can also be understood from the perspective that the rejection of Christianity cannot be separated from history. Roughly, this rejection can only be part of the vast stretch of territory of the unitary state of the Republic of Indonesia, and may also be a prejudice. This feeling of inner pull-push is an awareness of the Church to the environment or terrain around the Church that needs attention from it. The church is indeed seen as the other, not from the world, but it is a citizen of the world. The church realizes that it must be present for the world, even though it tends to pay more attention to the struggles of Church itself. The text of Jeremiah 29: 7 is a theological reference for building and moving the spirituality of the Church into concrete works of faith for its environment and situation around. The Church's faith work in its environment actually helps to overcome the nation's struggle, which inevitably has an impact to the continuity of the Church's presence.

Keywords: Church work; Mission; National resilience; Prosperity; Wealthy.

\section{Pendahuluan}

Bangsa Indonesia telah merdeka selama 75 tahun, tetapi perjuangan mewujudkan kehidupan masyarakat dalam alam yang adil untuk kehidupan sosial, pendidikan, ekonomi, kesehatan belum selesai bahkan belum beres. Terwujudnya kehidupan tadi masih menjadi impian besar tetapi tidak mustahil. 
Agaknya belum ada sinergitas dan kebersamaan perjuangan para anak bangsa secara jujur. Masih ada kecurigaan antar kelompok yang sifatnya primodial, yakni kelompok suku dan ras yang kental dengan cerita prototipenya, kelompok agama dan keyakinan, kelompok elit dan kaum kebanyakan, dan masih banyak kelompok lainnya lagi. Belum lagi beratnya mewujudkan gerak bersama dalam sinergitas kerja membangun bangsa oleh segenap anak bangsa, duka bangsa terus bertambah. Bentangan nusantara yang luas ini berada dalam "cincin api" (ring of fire) serta pergerakkan lempengan yang terus aktif, yakni lempang Asia, lempeng Eurasia, dan Indo-Australia-Pasifik. Kondisi geografis itu terus menjadi fenomena, karena penuh misteri alam, di mana berpotensi adanya bencana alam.

Dalam era pergumulan bangsa, hal ini menjadi keprihatinan yang kuat dan mendasar bagi segenap warga negara. Warga gereja juga adalah warga negera, yang turut merasakan kerinduan iklim adil dan makmur yang belum terjadi. Kerinduan tersebut harus diatasi dan diselesaikan. Semua elemen masyarakat diajak dan didorong berperan untuk memulihkan maupun membangun bangsa ini. Membangun dalam sipirit keadilan berarti tidak dibenarkan berjuang untuk hidup adil dan makmur bagi satu golongan atau kelompok tertentu. Indonesia adalah negara dengan jumlah penduduk yang besar. Upaya pemerataan hidup sejahtera terus dilakukan untuk segenap rakyat. Indonesia boleh berbangga sebagai negara besar, akan tetapi ketahanan bangsa ini dapat terwujud apabila kehidupan rakyatnya hidup makmur. Jadi kemakmuran rakyat dan ketahanan bangsa untuk konteks Indonesia saat ini merupakan jalinan kuat bagaikan dua sisi dari sebuah koin mata uang. Adanya kesenjangan sosial dan ekonomi dapat menjadi sentimen kuat sebagai pemicu yang berpotensi munculnya pemberontakan atas nama ketidakadilan.

Memerhatikan pergumulan bangsa di atas, Gereja tidak boleh tinggal diam dan berpangku tangan. Pergumulan bangsa mesti disambut sebagai bentuk keprihatinan Gereja. Keprihatinan itulah yang akan melahirkan dorongan batin dalam spiritualitas baru. Gereja memandang dunia sebagai realitas tempat tinggal yang dapat memberi kesejahteraan bagi dirinya. Gereja, sebagai persekutuan orang percaya, terlahir dari karya Roh Kudus, namun bukan berarti tidak bersentuhan dengan materi, bahkan Gereja sangat membutuhkannya. Jadi paradigma berpikir harus diluruskan dengan menegaskan bahwa Gereja pun hidup dari materi, oleh sebab itu Gereja dipanggil tidak untuk mengutuk dunia, melainkan bekerja dan memberkati dunia yang dipijaknya. Gereja tidak boleh 
hidup secara eksklusif dan harus membebaskan dirinya dari tudingan sebagai kaum lain di negeri ini. ${ }^{2}$

\section{Metode Penelitian}

Melalui penelitian terhadap teks pilihan, penulis akan memerlihatkan bahwa teks dapat memberi pertimbangan misi gereja dalam konteks sosial politik masyarakat Indonesia saat ini. Sedangkan upaya untuk meninjau lebih dalam terhadap teks secara kritis guna memeroleh inspirasi yang relevan, penulis akan menggunakan pendekatan kritik sejarah. ${ }^{3}$ Penulis merasa perlu dengan pendekatan itu, mengingat bidang kehidupan (sitz im leben) di mana Yeremia melaksanakan tugas kenabianya tidak terlepas dengan kehidupan istana serta politik luar negeri. Warna politik itu memang cukuplah kental, yang memberi andil Yehuda pada akhirnya berada di tanah pembuangan. Dan nasib orang buangan di negeri asing tentulah merasa sebagai koloni yang tak berarti. Umumnya nasib seperti ini sangat rentan terhadap berbagai kabar yang tidak jelas, termasuk adanya kabar bahwa mereka akan segera kembali. Oleh kabar itu menjadi konteks sapaan surat Yeremia guna mengarahkan kehadiran dan kehidupannya tetap berarti sepanjang entah kapan mereka kelak kembali ke tanah airnya. Kemudian hasil dari penelusuran teks, kiranya beroleh inspirasi iman yang memiliki nuansa sosial politis bagi penduduk Yehuda di tanah asing, yakni agar terlibat aktif membangun daerahnya. Inspirasi yang terbangun selanjutnya menjadi refleksi teologis. Artinya, dari tinjauan teks tersebut hendak membangun spiritualitas baru bagi gereja dalam rangka kehadirannya di nusantara ini. Memberi sumbangsih atau muatan nilai bagi makna kehadiran Gereja yang menurut Yohanes "bukan berasal dari dunia ini” (15:19). Sementara dari konteks Indonesia dari sisi kehidupan masyarakat secara sosial politik akan menjadi perhatian dan alamat dari konkritisasi yang bertolak dari refleksi itu.

\section{Pembahasan dan Hasil}

Konteks Teks.

Nas yang akan penulis teliti untuk menjadi titik pijak karya Gereja di era saat ini dipilih dari Yeremia 29:7, "Usahakanlah kesejahteraan kota ke mana kamu Aku buang, dan berdoalah untuk kota itu kepada TUHAN, sebab

${ }^{2}$ Hery Susanto, “Gereja Yang Berfokus Pada Gerakan Misioner,” FIDEI: Jurnal Teologi Sistematika dan Praktika 2, no. 1 (2019): 62-83.

${ }^{3}$ Arif Wicaksono, "Pandangan Kekristenan Terhadap Higher Criticism," FIDEI: Jurnal Teologi Sistematika dan Praktika 1, no. 1 (2018): 115-131. 
kesejahteraannya adalah kesejahteraanmu". Ayat tersebut tentu tidak bisa dipahami secara berdiri sendiri, atau bahkan sengaja mengabaikan perikop tempat ayat itu duduk. Sebenarnya cukuplah panjang perikop yang menjadi latar untuk akhirnya dapat memahahi pesan teks itu. Pasal 29 merupakan surat nabi Yeremia kepada para tua-tua yang masih ada/hidup dan terangkut dalam pembuangan ke Babel (tahun 597 sM). Tentu surat itu tidak terbit tanpa ada yang melatarbelakanginya, atau hal yang mendorong pada gilirannya Yeremia harus menulis suratnya. Dalam upaya menemukan konteks teks penulis sedikit membuat analisis sosio-historis agar diperoleh bayangan Sitz im Leben (bidang kehidupan) yang terekonstruksi. Tentu untuk membangun rekonstruksi Sitz im Leben yang baik pastilah keseluruhan kitab harus diperhatikan. Tetapi penulis sedikit membatasinya dengan membuat konstruksi konteksnya dari kitab Yeremia, yakni hanya sebatas hingga surat itu terbit dan dialamatkannya. Berbagai informasi raja dalam zamannya menjadi data yang dipertunjukkan menjadi narasi menuju terungkapnya harapan dan tujuan surat itu terbit.

Perhatikanlah narasi yang melatarbelakangi teks tersebut. Setelah kematian raja Yosia di kerajaan Israel Selatan atau Yehuda, ia digantikan oleh anak-anak (Yoahas alias Salum, Elyakim/Yoyakim, Zedekia) dan cucunya (Yoyakhin, putra Yoyakim). Amat disayangkan karena para pengganti baginda Yosia itu tidak hidup dengan takut akan Tuhan. Kepemimpinan mereka tidak membawa kerajaan Israel Selatan untuk setia dan hidup mengandalkan Tuhan. Baik raja Yoahas (Yer.22:11) dan Yoyakim, mereka menjalankan kekuasaannya dengan sangat tidak adil dan tidak jujur. Sebenarnya Yoahas adalah adik dari Yoyakim. Agaknya di istana atau di kalangan kerajaan ada dua "partai", yakni yang pro Mesir dan yang anti Mesir. Karena Yoyakim pro Mesir, sehingga yang naik tahkta adalah Yoahas. Dia menjadi raja menggantikan ayahandanya hanya tiga bulan. Tapi sayang, ibadahnya ia lebih memuja banyak dewa-dewi. Singkat cerita, kerajaan Yehuda kemudian dikepung dan diserang pasukan Mesir. Nanti setelah Yoahas ditangkap dan diasingkan ke Mesir, baginda Firaun Nekho mulai menarik pajak yang tinggi. Yoahas dibiarkan tetap hidup selama dipengasingan sampai mati. Setelah Yehuda ditahklukan, Kerajaan Mesir lalu mengangkat Yoyakhim sebagai raja Yehuda (609-598 sM). Raja boneka Mesir, Yoyakim pun dalam menjalankan kuasa dan kewenangnnya tidak mencerminkan seorang raja yang layaknya mengenal Tuhan. Dengan cara yang tidak jujur dan tidak adil ia membangun kerajaan sehingga sangat menyengsarakan hidup rakyatnya (22:13-16). Memerhatikan tindakan Yoyakim yang kerap menindas orang miskin, mendorong Yeremia terus menegur dan memeringati raja. Juga memberi 
peringatan bahwa kematiannya tidak akan ditangisi rakyat, bahkan matinya pun bakal seperti orang membuang bangkai keledai (22:17). Karena Yeremia dan nabi lain, seperti Uria, selalu menegur dan mengkritisi Yoyakim, terancamlah nyawa mereka. Sebagai bentuk reaksi penolakannya yang tidak mau mendengar teguran nabi, Yoyakim merampas gulungan kitab itu lalu dipotong-potong dengan belatinya sebelum dibakar. Tetapi untunglah Baruks berhasil menyalin ulang kitab tersebut. Kerasnya penolakan sang raja juga sampai-sampai para pembesar kerajaan yang peduli dengan para nabi tidak mampu melindunginya. Yeremia di mata raja dipandang selalu menentang kebijakan politiknya, sehingga mereka menganjurkan agar para nabi itu menyembunyikan diri, dan dengan terpaksa Yeremia pun akhirnya menyembunyikan diri (36:5). Juga nabi Uria terpaksa lari ke Mesir, namun para pesuruh Yoyakim terus mengejar dan mereka berhasil membunuhnya.

Semasa Yoyakim masih menjadi raja tahklukan Mesir, kerajaan Babel di bawah kuasa baginda Nebukadnezar muda mulai bangkit sebagai kerajaan adi kuasa baru. Lagi-lagi di istana Yehuda muncul dua golongan. Golongan pertama lebih banyak adalah yang lebih condongn untuk melakukan perlawanan kepada Babel dengan bantuan Mesir. Golongan ini didukung Yoyakim. Sementara golongan lain mengendaki agar Yehuda jangan melakukan perlawanan dan rela untuk takhluk saja kepada Babel. Yeremia lebih mendukung pemikiran golongan ini (Yer.25). Nabi mengingatkan, bahwa percuma saja melakukan perlawanan terhadap Nebukadnezar, karena ia adalah hamba Tuhan (27:6). Di bagian lain Mesir melakukan perlawanan terhadap Babel, tapi akhirnya dikalahkan Babel di Karkemis (42:2 dst., 605 sM). Dengan kekalahan Mesir, berakhir pulalah penahklukan Yoyakim dari Mesir, tapi sekarang nasib Yehuda dalam ancaman dan pengepungan pasukan Babel. Melihat kekuatan perang pasukan baginda Nebukadnezar, menyerahlah Yoyakim. Kini dirinya menjadi tahklukan Nebukadnezar. Mulanya Yoyakim akan dibuang ke Babel, tapi mungkin 'pintar-pintarnya' dia, agaknya sok setia akhirnya Nebukadnezar tetap menjadikan dia raja. Yang diangkut di Babel hanyalah sebagian kekayaan dalam bait Allah serta beberapa kaum ilmuan yang terpadang. Dari sekian orang terpandang yang diangkut ke Babel itu, menurut tradisi, diantaranya Daniel dan kawan-kawan. Rupa-rupanya kesetiaan Yoyakim hanya berlangsung sekitar tiga tahun. Yehuda mulai menghentikan kiriman upeti kepada Babel, lalu mulai percaya diri dalam keyakinan bantuan Mesir. Lagi-lagi sejumlah orang di istana bersedia berjuang untuk melakukan pemberentokan terhadap Babel dengan bantuan Mesir. Keadaan penduduk makin sulit, sehingga dalam situasi demikian 
pertolongan Tuhan sebagai upaya melepaskan diri dari Babel tidak boleh diharapkan. Justru sebaliknya, Yeremia, lebih mengharapkan agar Yehuda menerima situasi saat ini serta merelakan diri untuk tetap tahkluk kepada Babel.

Dengan mengharapkan datangnya bantuan Mesir, Yoyakim melakukan perlawanan atau pemberontakan terhadap baginda raja Nebukadnezar. Baginda Nebukadnezar sangatlah marah karena pengkianatan Yoyakim. Akhirnya Nebukadnezar mengirim pasukan dan mengepung kota Yerusalem. Dalam pertempuran melawan pasukan orang Kasdim (Babel), Yoyakim tewas. Mayatnya diseret ke luar kota Yerusalem dan diperlakukan seperti orang mau mengubur keledai (22:18-20). Tidak ada upacara perkabungan nasional, demikian juga tidak ada ratap kesedihan atas kekalahan dan kematian Yoyakim.

Setelah kematian Yoyakim, kerajaan Babel mengangkat 'raja boneka' baru untuk Yehuda yakni Yoyakhin, yang juga disebut Yekhonia atau Konya. Di era Yoyakhin tidak banyak cerita yang mengemuka, mungkin karena umur pemerintahannya hanya tiga bulan. Sama lamanya dengan raja Yoahas, pamannya. Yang jelas bahwa ia juga hidup dan menjalani tugasnya dengan tidak takut pada Tuhan. Dan akibat dosanya itu, Tuhan memakai Nebukadnezar untuk menyerang Yehuda. Saat pengepungan kota masih berlangsung, Yeremia tetap mendesak agar Yoyakhin menyerah saja (13:18-19; 22:24). Akhirnya Yoyakhin bersama ibu suri, para pejabat dan tua-tua atau imam-imam, mereka menyerahkan diri. Sebagai tawanan mereka dideportasi ke Babel, juga beserta beberapa barang berharga yang berhasil diangkut dari bait Allah. Ikut juga dalam rombongan yang dibuang itu nabi Yehezkiel. Peristiwa itu terjadi pada tahun 597 sM.

Meskipun Yoyakhin beserta ibu suri dan para pejabat mulia sudah diasingkan ke Babel, maharaja Nebukadnezar masih membiarkan kerajaan Yehuda berdiri, meski dengan status yang lain. Artinya tidak lagi sebagai kerajaan yang memiliki kedaulatan yang penuh. Dan raja yang menggantikan Yoyakhin adalah pamannya sendiri, Zedekia. Ia raja terakhir untuk Yehuda dan memerintah cukup lama, tahun 598-586 sM. Penulis kira cukup uraian sejarah menjelang akhir periode kerajaan Yehuda, Israel Selatan. Tulisan ini tidak lagi bercerita banyak tentang keadaan hingga berakhirnya masa pemerintahan Zedekia, karena di era ini surat Yeremia dikirimkan untuk bangsa Yehuda yang berada di tanah pembuangan.

Kini setelah menoleh sejenak suasana politik dalam negeri yang ternyata tidak terlepas dari ketaatan-Nya kepada Tuhan, hal itu memberi dampak pada cara Tuhan turut bertindak dalam situasi politik keamanan internasional. Kini 
perhatian pada teks tema yang berada dalam pasal 29. Sengaja menyoroti ayat 27 menjadi wacana teologi bagi Gereja memaknai kehadirannya di nusantara ini. Pasal 29 berisi dua bagian surat yang terpisah namun merupakan gambaran sikap sekaligus ajakan Yeremia terhadap umat Tuhan di Babel. Surat pertama ayat 1-23, dan surat kedua kepada Semaya orang Nehelam, ayat 24-32. Pada surat yang pertama merupakan surat Yeremia kepada mereka yang sudah mengalami deportasi yang pertama (597 sM). Surat tersebut ditujukan kepada kaum Israel melalui para tokoh, yakni tua-tua, para nabi, dan para imam. Bisa jadi, meskipun mereka dalam pergumulan psikis, spiritual dan fisik, mereka kiranya tetap hadir sebagai pemimpin dan pengayom di tengah-tengah umat Allah yang merasa hidup merana di tanah asing. Mereka kiranya tidak terprovokasi oleh ajaran dan hasutan nabi palsu sehingga memberi arahan yang salah kepada umat-Nya. Mereka harus tegar dan memiliki keyakinan yang jauh lebih kuat serta cerdas dalam menyikapi situasi buruk yang sementara dialami. Melalui mereka juga kiranya mampu menumbuhkan spiritualitas ketabahan, atau spiritualitas tahan banting agar tidak makin lemah oleh tekanan psikis akibat situasi sosial yang sulit, dan tetap menemukan bahwa hidupnya tidak mengalami penolakan Allah.

Yeremia memaklumkan, bahwa pengalaman sekaligus masa deportasi umat oleh Tuhan (ay.14) adalah cara Tuhan agar mereka pada akhirnya dapat melihat atau mengalami rancangan Tuhan, yakni šâlōm (shalom). Memang pembuangan itu memerlihatkan murka Tuhan yang kudus dan berkuasa serta yang dinyatakan-Nya melalui hukuman bagi umat-Nya. Akan tetapi bukan berarti tujuan murka Allah tersebut untuk menciptakan pemusnahan melainkan pengajaran dan pembentukkan. Kuasa Tuhan itu memerlihatkan kasih demi pembaharuan kehidupan umat di hadapan-Nya. Awalnya peristiwa pembuangan yang tak terbayangkan dan sulit dipahami umat. Umat yang cenderung dalam pendekatan yang logis sehingga sulit dipahami, over one's head. Seolah semua menjadi momen kekalahan Allah atas dewa-dewi Babel. Tetapi Yeremia membantah pemahaman yang demikian, bahwa Babel adalah hamba Tuhan (27:6). Jawaban itu hendak menunjukkan bahwa Tuhan adalah Allah yang berkuasa atas semesta (27:5) dan bangsa-bangsa. Allah pun kelak akan menunjukkan keadilan-Nya dengan menghukum Babel (25:12), juga akhirnya bangsa-bangsa lain yang tidak mengenal Allah (46-51). 


\section{Rahmat dalam Pembuangan.}

Hukuman Allah terhadap umat-Nya harus berlangsung. Tetapi sebagaimana disinggung di atas, bahwa penghukuman tersebut bukanlah dalam rangka pemusnahan, melainkan pembaharuan perjanjian. Allah tetap hadir bagi umat-Nya, demikian pula Allah hendak menjadikan mereka supaya tetap mengenal dan hormat pada Allah-Nya. Allah masih terus melangsungkan karya demi mewujudnyatakan rencana-Nya atas dunia ciptaan dan milik-Nya. Pemilihan terhadap Israel tetap terus dan tidak terhalang oleh karena pelanggaran yang dibuatnya. Sehingga walaupun dalam pembuangan, bukan berarti kekalahan Allah atas dewa-dewi bangsa-bangsa lain, justru menunjukkan kuasa dan kedaulatan atas semesta dan semua yang dianggap ilah oleh bangsabangsa. Dengan demikian, bahwa keberadaan atau kehadiran-Nya tidak hanya berada dalam area Yehuda saja, melainkan di atas muka bumi di mana manusia hidup. Maka kalau kemudian Israel berada di negeri asing, bukan berarti Allah tidak ada dan tidak bersama mereka. Pemencaran umat melalui peristiwa pembuangan bolehlah dipandang sebagai cara Allah hendak menghadirkan suasana shalom untuk semesta ini. Dengan demikian, pembungan kiranya dipandang oleh umat-Nya sebagai bagian dari cara Allah hendak memberkati dunia, dan melalui Israel sebagai alat dan saluran berkat-Nya. ${ }^{4}$

Peristiwa umat yang terbuang sehingga menerima surat Yeremia itu, seakan mengingatkan kita pada penyebaran umat dalam Kejadian 11. Lalu dengan dua perintah yakni, untuk bekerja dalam rangka mengusahakan kesejahteraan kota serta berdoa jugalah bagi kota. Kiranya terbayang bagi pembaca teks tersebut akan suasana dan kondisi kota di mana umat-Nya tinggal. Kuat kita duga, bisa jadi kota tersebut adalah kota yang tidak nyaman bahkan tidak aman untuk tinggal. Penulis membayangkan, seperti awalnya para transmigrasi dari Jawa yang dikirim ke berbagai tempat di luar pulau Jawa dan Bali, mereka masuk di suatu area pedalaman yang baru saja dibuka, daerah yang minim fasilitas sosialnya, meski baru dan belum lengkap, seperti pasar yang dibuka sepekan sekali, penerangan atau listrik tenaga diesel yang hanya hidup mulai pukul enam petang sampai pukul dua belas malam, sekolah dengan guru dan pustaka yang amat terbatas, puskesmas dengan fasilitas yang belum memadai dan dokter yang datangnya syukur-syukur seminggu sekali, dan lainlain keterbatasan yanga ada. Para keluarga transmigran harus bekerja keras agar

${ }^{4}$ David Eko Setiawan, "Konsep Keselamatan Dalam Universalisme Ditinjau Dari Soteriologi Kristen: Suatu Refleksi Pastoral," FIDEI: Jurnal Teologi Sistematika dan Praktika 1, no. 2 (2018): 250-169. 
mereka hidup dan bertahan serta sukses dari lingkungan yang baru saja dirambah oleh pemerintah.

Kiranya sedikit suasana seperti itu memberikan gambaran lingkungan baru bagi Israel di tanah pembuangan yang teramat gersang dan asing. Mungkin masih bersyukur kita di Indonesia, sekalipun asing, tetapi tidak gersang. Mereka, umat Allah, berada di tanah yang asing untuk bekerja dan berdoa demi kesejahteraan bersama, yakni dirinya dan orang lain dalam kota itu. 'Mental semangat' merupakan modal awal dan besar yang dapat melahirkan gairah kerja keras dan berpengharapan. Namun kerja keras dan pengharapan tersebut berangkat dalam penyerahan dan rasa syukur. Penyerahan dan rasa syukur kepada Tuhan terungkap dalam ajakan nabi untuk berdoa, yang tentunya bukan hanya melulu berdoa bagi dirinya. Sedia juga kiranya mendoakan masyarakat dan negeri asing tempat umat-Nya tinggal. Kesediaan untuk berdoa demikian hanya bisa terwujud bila umat mampu untuk memberi maaf atau berdamai kepada dirinya, Tuhan dan sesama. Rupanya spiritualitas yang harus terbangun demi tercapainya hidup sejahtera bersama adalah spiritualitas tahan banting 5 . Spiritualitas ini tidak membuat umat menjadi cengeng dan merasa terbuang, tapi sebaliknya merasa terutus untuk membuat rahmat-Nya memberi hidup sejahtera lahir - batin bagi semua mahkluk.

Apabila mengikuti pandangan Carroll, bahwa Alkitab memberi gambaran yang sangat menarik dalam potensi kehidupan masyarakat yang beragama, di mana shalom pada suatu daerah dapat terwujud disebabkan oleh warganya yang hidup bahagia dalam rumah tangga, hidup dalam ketaatan pada hukum, tekun bekerja dan berdoa. ${ }^{6}$ Kehadiran umat menjadi penentu kemajuan, kemakmuran dan suasana harmoni, singkatnya shalom, dari suatu daerah (kota) di mana mereka tinggal. Mereka disadarkan bahwa, diri merekalah yang menentukan kebaikan (shalom) bagi dirinya dan lingkungan yang satu sama lain tidak bisa terpisahkan. Dengan demikian, lebih luas, bahwa semesta lebih khusus bumi yang belum tersentuh atau terpijak pagi umat-Allah ini bukanlah tanah yang asing bagi Allah. Lalu dengan datangnya umat Allah ke sana masyarakat akhirnya merasakan sentuhan Allah. Yakni sentuhan yang memberi hidup dan harapan. Hadirnya umat Tuhan di suatu negeri tidak usahlah berpolemik ${ }^{7}$, bahwa tinggal di sana akan memakan waktu yang lama atau singkat. Yang perlu

\footnotetext{
${ }^{5}$ E Martasudjita, Spiritualitas Tahan Banting (Yogyakarta: Kanisus, 2009), 81.

${ }^{6}$ Robert P Carroll, Jeremiah, A Commentary (London: SCM Press, 1986), 556.

${ }^{7}$ Ibid., 556-557.
} 
bagi mereka adalah mencintai tanah yang asing, dengan demikian dapat membangun kehidupan yang baru dan bersejahtera.

\section{Gereja di Tanah Asing.}

Bagian ini dimulai dengan komentar kecil yang menurut penulis sendiri menarik. Suatu ketika seorang berkomentar bahwa, "Kota ini tidak akan maju". Kotanya memang kecil. Lalu penulis tanya alasannya dan ia menjawab, "Ya, karena di kota tidak ada orang Cina. Mereka dilarang tinggal di sini. Itu sebabnya kota ini tidak akan maju. Coba lihat di kota lainnya yang di sana. Di sana sudah bisa lebih maju, karena ada orang Cinanya". Komentar yang disampaikan itu penulis kira tidak dibuat berdasarkan hasil survei yang dikerjakan secara akademis, jadi jelas tidak bisa dipertanggungjawabkan secara ilmiah pula. Tetapi terlepas benar tidak muatan komentar itu, yang jelas asumsinya kota tersebut akan lebih maju apabila ada suku atau orang ini-itu. Mungkin dari situ bisa pula kita beralegori, kota ini tidak akan maju kalau tidak ada orang Kristen. Kalau alegori ini diterima, menarik. Mungkin kita akan setuju. Setuju dengan dorongan sipiritualitas untuk hidup menjadi bekat.

Penulis kira kita tidak mengatakan bahwa Gereja ${ }^{8}$ sementara ini berada di tanah pembuangan. Seakan Indonesia menjadi tanah pembungan bagi Gereja. Tidak, melainkan hadir di tanah yang ke sana juga Allah akan memberkati dan memberikan shalom. Melalui pemahaman teks Yeremia 29:7, umat kristiani yang telah - kiranya - terbekali serta dibaharui spiritualitasnya, akan selalu terdorong, termotivasi dan rindu membawa dampak hidup damai, kini makin terdorong berkarya nyata. Suatu karya iman yang lebih peduli terhadap lingkungan dirinya.

Kesadaran akan kekurangan pada lingkungan yang dilihat dan dialami tidak membuat dirinya makin menyalahkan bahkan mengutuknya. Kalau demikian, pemahaman yang kita peroleh dari teks itu, agaknya kali ini bukan mendorong diri kita yang berbuat lebih banyak untuk menyelamatkan hidup diri kita baru menolong orang lain. Tetapi justru mendorong Gereja menolong lingkungan - dengan kerja dan doa - bukan supaya lingkungan menjadi lebih baik, lalu Gereja hidupnya susah. Justru dengan sendirinya, karena Gereja melakukannya dengan penuh ketulusan dan kejujuran Gereja akan mengalami dampaknya, yakni turut menjadi baik atau sejahtera. Kesadaran adanya ketimpangan dari harmoni kehidupan pada lingkungan juga bukan berarti gereja

${ }^{8}$ Penulisan kata Gereja dengan huruf awal G kapital menunjuk pada orang, tetapi bila sebaliknya "g" (huruf kecil), kata itu menunjuk pada gereja sebagai lembaga atau institusi. 
takabur dengan berasumsi merasa sudah lebih baik. Ketimpangan harmoni tadi tentu berdampak pada dirinya dan menjadi keprihatinan bangsa. Berbagai ketimpangan harmoni kehidupan antara lain, iklim hidup yang tidak nyaman oleh kenyataan kesenjangan relasi sosial, individualistik karena kaget teknologi infomatika, kerusakan lingkungan dan potensi bencana, kemiskinan oleh struktur dan sistem, masyarakat yang rentan penyakit, rentan terhadap gizi buruk, keadilan untuk beroleh layanan atau akses pendidikan, kesehatan, hukum dan penghidupan lainnya. Sedikit menyinggung kerusakan lingkungan yang berpotensi pada bencana alam. Soal itu juga menjadi perhatian serius bagi gereja merubah dan upaya membangun citra melalui teologinya. Gereja dengan teologi Yahudi-Kristen pernah berkali-kali menerima terpaan kritik, bahwa manusia hadir terpisah dengan alam, sehingga mengabaikan kesucian alam, akibatnya bebas untuk dieksploitasi secara besar-besaran. ${ }^{9}$ Oleh ancaman ketimpangan harmoni tadi, umat kristiani sendiri tak terpungkuri turut teracam bahkan mengalami kehidupan berat seperti sudah disinggung sebelumnya.

Pekerjaan untuk memulihkan lingkungan menjadi shalom bukanlah pekerjaan yang mudah, bahkan bisa ditangani seorang diri. Sebuah lembaga atau denominasi gereja mestilah sadar, bahwa dirinya bukanlah superman yang sanggup membalik dunia buruk dan kejam manjadi dunia yang baik dan ramah. Tetapi kiranya kehadiran dan pergaulan orang Kristen sebagai Gereja membuat dirinya dipercaya dan menjadi sahabat simpatik bagi orang lain; alih-alih menganjurkan insan kristiani mewujudkan shalom bersama dan di dalam masyarakat. Inilah saatnya bagi insan beriman menunjukkan karya kasih kepada sesama, bukti imannya, ternyata mendatangkan kasih kepada dirinya sendiri.

Banyak hal tata kelola dalam masyarakat dijumpai oleh Gereja yang barangkali menurut kita agaknya tidak sejalan dengan prinsip Injili, sehingga melahirkan dampak atau bencana dan ketidakharmonisan kehidupan. Tetapi gereja sendiri masih sibuk dengan dogma sejarah keselamatan atau dogma yang memahami bahwa di luar gereja tidak ada keselamatan, extra ecclesiam nulla salus, akibatnya karya gereja berbelarasa atau karya iman gereja tidak ada. Dan kalaupun ada dipandang sebagai upaya pemenuhan amanat agung yang bertarget. Targetnya adalah terbaptis banyak jiwa. Jadi pekerjaan pada sisi pewartaan verbal dan ritual seremonial masih lebih dominan. Artinya semua proyek itu dipergunakan bagi kepentingan gereja. Teologi Yeremia yang memberi inspirasi kuat bagi gereja di Indonesia justru mengajak berpikir sebagai gereja yang mau

\footnotetext{
${ }^{9}$ Robert Patannang Borong, "Kronik Ekoteologi Dalam Konteks Krisis Lingkungan," Stulos: Jurnal Teologi 17, no. 2 (2019): 197-198.
} 
masuk dan bergaul dengan pergumulan masyarakat. Orientasinya bukan untuk kepentingan dirinya, melainkan bagi orang lain atau lingkungan yang menjadi sasaran tetapi juga diajak sebagai subjek untuk bersama mewujudkan shalom.

Kehadiran Gereja yang mau bersentuhan dengan masyarakat, tentunya tidak akan menghilangkan kekudusan dirinya, melainkan hadir sebagai yang kudus, dengan demikian melalui karya-karyanya ia memungkinkan meneruskan rahmat Allah. Inilah Gereja yang merayakan sakramentalnya. Oleh sebab itu, Gereja sangat perlu mengenal pergumulan lingkungannya. Pergumulan lingkungan itulah konteksnya. Menggereja masa kini tidak lepas dari konteks. Dan konteks kita adalah kemiskinan, ketidakadilan, lingkungan hidup, yang semua itu tidak lepas dengan nilai-nilai budaya yang memelihara keharmonisan. Itu sebabnya, Gereja mampu memelihara semangat silaturahmi dan gotong royong. Dan melalui sentuhan politis dalam kehidupan berbangsa terhadap konteks itu, Gereja menghidupi nilai-nilai Pancasila dalam realitas kesehariannya serta mengajak anak bangsa lainnya mengawal penegakkan nilainilai itu. ${ }^{10}$ Sehingga keprihatinan hidup bukan hanya dirasakan oleh warga gereja, melainkan oleh semua lapisan masyarakat. Dan akhirnya semua rindu untuk keluar dari kemelut dan pergumulan bangsa, yakni supaya hidup sejahtera secara lahir batin, adil dan makmur. Mungkin saja semangat silaturami dan gotong royong mulai pudar. Hidayat merasakan suasana itu dan menurutnya, blok-blok sosial dalam di masyarakat salah satu penyebab utamanya adalah rasa keagamaan yang begitu kuat. Adanya rasa keterpanggilan yang dalam untuk membangun penghayatan citra iman melahirkan komunitas keagamaan. ${ }^{11}$ Tetapi suasana itupun salah satu pergumulan bangsa. Juga dalam studi Agus, ia menduga kuat bahwa agama dapat turut memberi kontribusi ketidakharmonian dalam masyarakat yang plural karena pendekatannya yang bersifat "aspirasi" dalam ruang publik, yakni 'pemaksaan' diberlakukannya tata kehidupan sesuai dengan akidah atau dogmanya. ${ }^{12}$ Lebih lanjut Agus menawarkan pendekatan "inspirasi", suatu pendekatan yang tidak mengedepakan semangat mewujudkan cita-cita agama dalam semua dimensi dan struktur masyarakat. Pendekatan ini lebih lanjut menurutnya lebih memberi semacam 'ilham' atau pengaruh bagi kehidupan masyarakat, berbangsa dan berperikehidupan. Pendekatan ini bukan

${ }^{10}$ Ebenhaizer I. Nuban Timo, Meng-Hari-Ini-Kan Injil Di Bumi Pancasila: Bergereja Dengan Cita Rasa Indonesia (Jakarta: BPK Gunung Mulia, 2017), 464.

${ }^{11}$ Komaruddin Hidayat, “Agama Dan Uang," Harian Kompas (Jakarta, n.d.).

${ }^{12}$ Agus Supratikno, "Peran Politis Agama Dalam Konteks Indonesia Yang Plural: Aspirasi Atau Inspirasi," Waskita: Jurnal Studi Agama dan Masyarakat 3, no. 1 (2016): 135139. 
mewujudkan cita-cita agama. Pendekatan ispirasi menghadirkan gereja memberi kontribusi nilai-nilai kristiani memberi pengaruh dalam etika berbangsa, bermasyarakat, bernegara, bahkan sikapnya terhadap lingkungan (etika lingkungan). ${ }^{13}$

Bahwa dalam sejarahnya bangsa kita telah mengenal dan memiliki modal sosial, yakni semangat kebersamaan (gotong royong), rasa solidaritas dan kekeluargaan yang tinggi. ${ }^{14}$ Sedih bila modal ini lambat laun hilang. Namun bukan berarti tidak mungkin kembali dibangun. Kemelut bangsa bukan hanya persoalan orang Kristen, melainkan semua masyarakat ikut merasakannya. Mungkin dari situasi sepenanggungan itu pula gereja memulai menabur dan menyemai modal bangsa tadi. Bersama membina dan dengan uletnya dikerjakan bersama. Bersama pula berjuang karena tidak pernah kehilangan harapan akan hidup yang lebih baik. Rasa religiositas yang dimiliki menyatu dan memberi spirit baru untuk bersama bekerja di tengah pluralitas yang sangat beragam.

Rasa keterasingan ataupun merasa terhindari sebagai orang Kristen sehingga kurang disambut dalam lingkungan, harapannya bukan kemudian Gereja lalu berbalik badan. Gereja atau orang Kristen yang berbalik badan sama saja membuat keterpisahan dirinya dari nilai dan budaya masyarakat. Schacht mengatakan, memeisahkan diri atau mengalienasi diri, meruapakan sikap tidak adanya solidaritas pada lingkungan ia berada. ${ }^{15}$ Kesadaran adanya lingkungan, adalah juga kesadaran pluralitas tak menghambat membina karakter sadar pluralis, dengan demikian dapat mengakui bahwa mereka yang berbeda budaya dan keyakinan agamanya mempunyai nilai-nilai yang sama. Mereka juga merindukan kejujuran, keadilan, kebesaran dan kebaikan hati serta bersedia memberi maaf. Sama-sama juga menolak kekerasan, penindasan, kemiskinan, menolak ketidakadilan dan kekejaman.16 Modal sosial keramahtamahan yang pernah terpuji tetap bertahan mendapat spirit untuk membantu memecahkan masalah dalam masyarakat dan bangsa.17

Dengan demikian, berangkat dari keperihatinan dunia tempat dirinya hadir, terdorong oleh semangat pergerakan pemahsyuran Injil Kristus, gereja tidak menolak pluralitas. Karena begitulah dunia tempat di hadir. Jadi meski ada penolakan terhadap dirinya, justru, menjadi cara pandang bagi gereja bahwa

${ }^{13}$ Ibid., 140-148.

${ }^{14}$ Eddy Kristiyanto, Sakramen Politik (Yogyakarta: Lamalera, 2008), 220.

${ }^{15}$ Richard Schacht, Alienasi (Yogyakarta: Jalasutra, 2016), 215.

${ }^{16}$ Franz Magnis Suseno, Etika Kebangsaan Etika Kemanusiaan (Yogyakarta: Kanisius, 2008), 28-29.

${ }^{17}$ Kristiyanto, Sakramen Politik, 220-222. 
dirinya dipilih dan diutus untuk pekerjaan yang lebih luas. Bukan hanya bekerja sebatas bagi kebaikkan kelompoknya sendiri. Rasa atau 'nasib' terasing bukan membuat dirinya memberontak terhadap mayoritas, ini yang tidak mungkin. Tapi mungkin akan memberontak atau menggugat Tuhan.

Keluhan gereja adalah keluhan masyarakat yang merindukan kebutuhan dasar terpenuhi, sejahtera dan keadilan sosial. Gereja menjadi saluran berkat Allah bagi bangsa ini; ia tanpa harus membawa identitasnya menjadi pelopor dan sumber inspirasi untuk menata membangun Indonesia, baik dalam dunia pendidikan, ekonomi, kesehatan, keadilan, sosial, bahkan politik. Diberkatilah Indonesia, bahagia pulalah gereja.

\section{Simpulan}

Akhirnya dalam kehadiran gereja di sini, gereja harus melihat bahwa dirinya adalah bagian dari tempat yang di atasnya ia juga hadir. Orang merantau cenderung ulet dan tekun agar dirinya dapat terus bertahan hidup. Ia tidak hanya berjuang untuk hari ini, melainkan untuk masa depan. Bahkan ada mimpi yang ia punyai. Ia mungkin harus mengabaikan sementara statusnya yang bukan sebagai penduduk dari ranah itu. Di sana ia harus mengolah tanah menjadi tanah pertanian yang pada akhirnya dapat memeroleh hasil pertanian berupa sayursayuran yang sebelumnya belum ada, tetapi kini dapat dinikmati penduduk setempat. Mungkin tadi dapat menjadi contoh cerita sederhana, tetapi dapat ditarik garis mulai dari pesan Yeremia terhadap gereja supaya punya peran berarti bagi lingkungan kehadirannya. Banyaknya keluhan karena rasa ketertolakan lingkungan atau dianggap sebagai orang asing yang dialami oleh beberapa gereja bukan disikapi dengan cara menghindar, kemudian mengisolasi diri dan pada akhirnya menjadi eksklusif. Gereja harus memerankan misinya sebagai akibat yang mau tidak mau telah berinteraksi dengan lingkungannya. Bisa jadi penolakan terhadap gereja karena belum maksimalnya interaksi positif dengan lingkungan. Interaksi dimaksud adalah menjadi bagian dari realitas sosial, politik, ekonomi dan tradisi-budaya. Sementara kita, mestinya, tahu ada yang 'kurang' dan memengaruhi nilai damai dan sejahtera dalam realitas itu. Yang kurang inilah yang perlu dicermati dan disikapi dengan cerdas oleh Gereja, misalnya dengan membangun dan memantapkan sosialitas Indonesia yang bersifat kekeluargaan. ${ }^{18}$ Sentuhan yang seperti ini lebih memerlihatkan kepribadian kristiani yang lebih cenderung tidak membangun konflik. Kekristenan menjadi model terbangunnya masyarakat Pancasila, yakni kepedulian, keramahan, kesantuan, kejujuran, kerendahan hati, kepedulian,

${ }^{18}$ I Made Priana, "Rekonstruksi Misi Gereja Di Indonesia Dari Perspektif Pancasila Sebagai Religiositas Sipil Indonesia," Waskita: Jurnal Studi Agama dan Masyarakat 3, no. 1 (2016): 124. 
gotong royong. Inilah karakter yang menjadi pintu masuk kehadiran dan peran lebih luas bagi dirinya. Sentuhan merupakan sikap setia Gereja akan panggilan terhadap Kepala Gereja, yang sekaligus menjadi nyata ketika mencoba dan memulai perannya sebagai warga bangsa dan Negaranya.

\section{Daftar Pustaka.}

Borong, Robert Patannang. "Kronik Ekoteologi Dalam Konteks Krisis Lingkungan." Stulos: Jurnal Teologi 17, no. 2 (2019).

Carroll, Robert P. Jeremiah, A Commentary. London: SCM Press, 1986.

Ebenhaizer I. Nuban Timo. Meng-Hari-Ini-Kan Injil Di Bumi Pancasila: Bergereja Dengan Cita Rasa Indonesia. Jakarta: BPK Gunung Mulia, 2017. Hidayat, Komaruddin. “Agama Dan Uang.” Harian Kompas. Jakarta, n.d.

Kristiyanto, Eddy. Sakramen Politik. Yogyakarta: Lamalera, 2008.

Martasudjita, E. Spiritualitas Tahan Banting. Yogyakarta: Kanisus, 2009.

Priana, I Made. "Rekonstruksi Misi Gereja Di Indonesia Dari Perspektif Pancasila Sebagai Religiositas Sipil Indonesia." Waskita: Jurnal Studi Agama dan Masyarakat 3, no. 1 (2016).

Schacht, Richard. Alienasi. Yogyakarta: Jalasutra, 2016.

Setiawan, David Eko. "Konsep Keselamatan Dalam Universalisme Ditinjau Dari Soteriologi Kristen: Suatu Refleksi Pastoral.” FIDEI: Jurnal Teologi Sistematika dan Praktika 1, no. 2 (2018): 250-169. https://doi.org/10.34081/fidei.v1i2.8.

Supratikno, Agus. "Peran Politis Agama Dalam Konteks Indonesia Yang Plural: Aspirasi Atau Inspirasi." Waskita: Jurnal Studi Agama dan Masyarakat 3, no. 1 (2016).

Susanto, Hery. "Gereja Yang Berfokus Pada Gerakan Misioner." FIDEI: Jurnal Teologi Sistematika dan Praktika 2, no. 1 (2019): 62-83.

Suseno, Franz Magnis. Etika Kebangsaan Etika Kemanusiaan. Yogyakarta: Kanisius, 2008.

Wicaksono, Arif. "Pandangan Kekristenan Terhadap Higher Criticism." FIDEI: Jurnal Teologi Sistematika dan Praktika 1, no. 1 (2018): 115-131. https://doi.org/10.34081/fidei.v1i1.6. 